\title{
Prevalence of metabolically unhealthy obesity, overweight, and normal weight and the associated risk factors in a southern coastal region, Iran (the PERSIAN cohort study): a cross-sectional study
}

Ghazal Zoghi ${ }^{1}$, Roghayeh Shahbazi ${ }^{2}$, Masoumeh Mahmoodi ${ }^{3}$, Azim Nejatizadeh ${ }^{4}$ and Masoumeh Kheirandish ${ }^{3^{*}}$

\begin{abstract}
Background: Obesity is a substantial risk factor for cardiovascular and metabolic diseases. Epidemiologic studies have shown that some obese and overweight individuals are metabolically healthy. We aimed to determine the prevalence of metabolically unhealthy obesity (MUO), metabolically unhealthy overweight (MUOW), and metabolically unhealthy normal weight (MUNW) in a southern coastal area of Iran, Bandare-Kong Non-Communicable Diseases (BKNCD) Cohort Study.
\end{abstract}

Methods: This population-based study included the participants of BKNCD, as part of the Prospective Epidemiological Research Studies in IrAN (PERSIAN). Metabolic health was defined as not fulfilling the metabolic syndrome (MetS) criteria.

Results: Among the 3917 participants in this study with the mean age of $48.29 \pm 9.39$ years, including 1691 (43.2\%) males, the age- and sex-standardized prevalence of MUO, MUOW, and MUNW was 13.9, 16.8, and 6.4\%, respectively. Binary logistic regression analysis revealed that the adjusted odds of all metabolically unhealthy states were higher in older age groups, except for MUO whose adjusted odds were lower in the 65-70 age group compared to the 55-64 age group. Illiteracy was significantly correlated with MUOW (adjusted OR: 1.43, 95\% Cl 1.09-1.87, P=0.010); however, it was not associated with MUO or MUNW. Higher body mass index (BMI) was significantly correlated with MUNW but it was not associated with MUOW or MUO. Higher waist circumference (WC) was also significantly associated with all metabolically unhealthy states.

Conclusion: The age- and sex-standardized prevalence of MUO, MUOW, and MUNW was 13.9, 16.8, and 6.4\%, respectively in the current study. Advanced age and higher WC were significantly correlated with all metabolically unhealthy states, while illiteracy and higher BMI were only associated with MUOW and MUNW, respectively. Metabolic health rather than weight loss should be the focus and objective of public prevention programs.

Keywords: Metabolic health, Obesity, Prevalence, Prospective Epidemiological Research Studies in IrAN (PERSIAN)

* Correspondence: kheirandishm@yahoo.com

${ }^{3}$ Endocrinology and Metabolism Research Center, Hormozgan University of Medical Sciences, Bandar Abbas, Iran

Full list of author information is available at the end of the article

C C The Author(s). 2021 Open Access This article is licensed under a Creative Commons Attribution 4.0 International License, which permits use, sharing, adaptation, distribution and reproduction in any medium or format, as long as you give appropriate credit to the original author(s) and the source, provide a link to the Creative Commons licence, and indicate if changes were made. The images or other third party material in this article are included in the article's Creative Commons licence, unless indicated otherwise in a credit line to the material. If material is not included in the article's Creative Commons licence and your intended use is not permitted by statutory regulation or exceeds the permitted use, you will need to obtain permission directly from the copyright holder. To view a copy of this licence, visit http://creativecommons.org/licenses/by/4.0/. The Creative Commons Public Domain Dedication waiver (http://creativecommons.org/publicdomain/zero/1.0/) applies to the data made available in this article, unless otherwise stated in a credit line to the data. 


\section{Introduction}

Although obesity is a major concern worldwide and epidemiological evidence suggests that obesity is an independent risk factor for many diseases including type 2 diabetes mellitus, cardiovascular diseases, nonalcoholic fatty liver disease, sleep apnea, hypertension, stroke, and several types of cancer [1-3], some individuals are metabolically healthy despite being obese. This is called metabolically healthy obesity (MHO), which is defined by the absence of metabolic abnormalities, such as dyslipidemia, hyperglycemia, and hypertension in individuals with body mass index (BMI) within the obesity range [4-6]. It has been reported that mild weight gain does not necessarily cause metabolic dysfunction when individuals are otherwise metabolically healthy. Similarly, weight loss may not necessarily decrease cardiometabolic risk in individuals with $\mathrm{MHO}$ and may even result in a contradictory response (e.g. a decline in insulin sensitivity instead of the expected increase) [7, 8]. Surprisingly, adipose tissue may protect against the adverse effects of metabolic syndrome [9].

The prevalence of MHO varies widely $(10-40 \%$ of all the obese); nevertheless, age, ethnicity, and geography do not account for such variety. Most definitions of $\mathrm{MHO}$ are based on the absence of metabolic syndrome (MetS) or some of its individual components [10]. Lack of a standard definition for metabolic health can be responsible for this disparity. Yet, in a collaborative analysis of 10 large cohort studies across Europe, MHO prevalence was reported $7-28 \%$ in women and $2-19 \%$ in men, despite using a harmonized MHO definition; obesity without any components of MetS and no previous cardiovascular disease diagnosis [11].

There is another concept referred to as metabolically unhealthy obesity (MUO); in spite of similar levels of total excess body fat compared to those with $\mathrm{MHO}$, the consequences of obesity have already developed in individuals with MUO [12-14]. Conversely, a cluster of metabolic abnormalities exists in many normal-weight individuals. These are referred to as metabolically unhealthy normal weight (MUNW), whose cardiovascular events and all-cause mortality appear to be comparable to those with MUO $[2,15,16]$.

Metabolic health seems to be more important than normal weight in preventing future cardiovascular events, with the metabolically healthy obese having similar outcomes compared to metabolically healthy normal weight individuals. Besides, most of the studies on these concepts lack two categories of individuals, namely metabolically healthy overweight (MHOW) and metabolically unhealthy overweight (MUOW). Therefore, in the current study we aimed to investigate the prevalence of MUNW, MUOW, and MUO and the associated risk factors in the PERSIAN Bandare-Kong Cohort Study.

\section{Methods}

\section{Participants and study design}

In this cross-sectional study, we evaluated participants of the PERSIAN Bandare-Kong Cohort Study, as part of the Prospective Epidemiological Research Studies in IrAN (PERSIAN) which has been previously described in detail [17]. The cohort study includes 4063 individuals aged 35-70 years, recruited between November 17, 2016 and November 22, 2018 from Hormozgan province, southern Iran. After exclusion of incomplete records and pregnant women, the baseline data of 3917 individuals were included in the final analysis of the current study.

\section{Data collection}

Face-to-face interviews were done by trained interviewers in order to collect sociodemographic data, including age, education, marital status, occupation, place of residence, and cigarette smoking. The cumulative calorie content of the daily ingested foods was also recorded as "daily calorie intake" using the food frequency questionnaire (FFQ) validated for the Iranian population [17]. For estimation of daily calorie intake, the portions of ingested foods were converted into gram weight multiplied by the energy/calorie content of each type of food per gram weight. Metabolic equivalent of tasks (METs) was used to report weekly energy expenditure.

A standard digital scale with measurement accuracy of $0.5 \mathrm{~kg}$ was used to weigh the subjects while they wore minimum clothing and no shoes. Height was measured with normally set shoulders while subjects were standing shoeless. Waist circumference (WC) was measured at the end of several normal breaths, at a level parallel to the floor, the midpoint between the top of the iliac crest and the inferior margin of the last palpable rib in the midaxillary line. WC was measured twice for each participant and the average was recorded. The largest circumference of the buttocks, at a parallel level to the floor, was measured as hip circumference (HC). All measurements were done with the same stretch-resistant tape to the nearest $0.5 \mathrm{~cm}$. Subjects were standing upright during the measurements, with arms relaxed at the side, feet evenly spread apart, and body weight evenly distributed. Waist-to-hip ratio (WHR) was calculated as WC divided by $\mathrm{HC}$ to the nearest 0.01 . BMI was calculated as weight in kilograms divided by the square of the person's height in meters to the nearest 0.01 . According to the WHO guidelines, BMI $<25 \mathrm{~kg} / \mathrm{m}^{2}$ was regarded as normal, $25 \leq \mathrm{BMI}<30$ as overweight, and $\mathrm{BMI} \geq 30$ as obese [18].

A standard mercury sphygmomanometer with an appropriate for arm circumference was used to measure blood pressure (BP) after $5 \mathrm{~min}$ of rest, in the seated position, with feet on the floor, and arm at heart level. 
The average of two measurements made at least $5 \mathrm{~min}$ apart was recorded.

Following overnight fasting, 5-ml venous blood samples were collected and fasting plasma glucose (FPG) was measured using the glucose oxidase method. Also, triglyceride (TG) and high-density lipoprotein (HDL) were measured for each participant using the enzymatic method. The details of sample collection and storage, as well as measurements have previously been published [17].

The International Physical Activity Questionnaire was used for the assessment of physical activity [19]. The weekly average of 24-h physical activities including leisure time activities, work, and exercise was categorized into 3 groups, namely low physical activity 24-36.5 METs, moderate (36.6-44.9 METs), and high ( $\geq 45$ METs) [20]. The wealth index, an estimation of the socioeconomic status, has previously been explained in detail. Based on this score, participants were graded and then classified into tertiles, including poor, average, and rich [21]. WHR was classified into low, moderate, and high according to the World Health Organization (WHO) separate cut-offs for men and women [22].

MHO was defined as BMI $\geq 30 \mathrm{~kg} / \mathrm{m}^{2}$ and not having MetS according to the criteria proposed by Meigs et al. [23] and Aguilar-Salinas et al. [24]. The National Cholesterol Education Program Adult Treatment Panel III (NCEP-ATP III) criteria for MetS [25], along with cutoffs for WC replaced by $\geq 95 \mathrm{~cm}$ in both men and women, was used as the Iranian-specific criteria [26, 27]. MHOW was defined as $25 \leq \mathrm{BMI}<30$ and not having MetS, while MHNW was defined as BMI $<25$ and not having MetS. Participants with $\mathrm{BMI} \geq 30$ and MetS were classified as MUO, those with $25 \leq \mathrm{BMI}<30$ and MetS as MUOW, and those with BMI $<25$ and MetS as MUNW.

\section{Data analysis}

The Statistical Package for the Social Sciences (SPSS) software (version 25.0, Armonk, NY: IBM Corp., USA) was used for data analysis. Mean, standard deviation, frequency, and percentages were used to describe the variables. The crude prevalence of MUO, MUOW, MUNW, MHO, MHOW, and MHNW was calculated by dividing the number of participants with each condition by 3917 (the total number of participants included in the study). Moreover, age- and sex-standardized prevalence (ASSP) was calculated through the direct standardization method using the Stata software version 15.0. Independent t-test was used to compare quantitative variables and Chisquared test to compare qualitative variables between healthy and unhealthy states. The binary logistic regression model was used to determine the factors associated with metabolically unhealthy states. All the potential factors with $P$-values $\leq 0.2$ in single correlations were simultaneously included in the multivariate logistic regression model using the "enter" method. For each group, the metabolically unhealthy state was coded 1 and the healthy state was coded 0 . For instance, MUO was coded 1 and MHO was coded 0 . Therefore, the odds of each metabolically unhealthy state were reported compared to its metabolically healthy state. $P$-values $<0.05$ were regarded as statistically significant.

\section{Results}

Of the 3917 participants included in the current study, 1691 (43.2\%) were male and 2226 (56.8\%) were female. Their mean age was $48.29 \pm 9.39$ (35-70) years. The ageand sex-standardized prevalence (ASSP) of MHO, MUO, MHOW, MUOW, MHNW and MUNW is illustrated in Table 1 . Based on the criteria proposed by Meigs et al. [23], the ASSP of MHO, MHOW, and MHNW was $10.4,22.3$, and $30.3 \%$, respectively while the ASSP of MUO, MUOW, and MUNW was found to be 13.9, 16.8, and $6.4 \%$, respectively. The highest prevalence of MUNW (16.9\%) and MUOW (25.7\%) was observed in the 65-70-year age group and MUO in the 55-64-year age group (17.2\%). In addition, MHNW (34\%), MHOW $(27.8 \%)$, and $\mathrm{MHO}(14.5 \%)$ were all the highest in the 35-44-year age group.

Age and weight were significantly higher in the MUNW group compared to the MHNW group. This was also the case for the MUOW group compared to the MHOW group, except for weight which was significantly higher in the MHOW group. Similarly, the aforementioned variables were higher in the MUO group compared to the MHO group; however, the difference regarding weight was not statistically significant. Daily calorie intake was surprisingly higher in the metabolically healthy groups (Table 2). In addition, the metabolically unhealthy states were most commonly observed in women, urban residents, those who were married, illiterate or unemployed, participants with moderate physical activity, and those who were at the extremes regarding wealth (the poor and the rich).

Binary logistic regression analysis revealed that the adjusted odds of all metabolically unhealthy states were higher in older age groups, except for MUO whose adjusted odds were lower in the 65-70 age group compared to the 55-64 age group. Illiteracy was significantly correlated with MUOW (adjusted OR [aOR]: 1.43, 95\% CI 1.09-1.87, $P=0.010$ ); however, it was not associated with MUO or MUNW. Higher BMI was significantly associated with MUNW but not with MUOW or MUO. Higher WC was also significantly correlated with all metabolically unhealthy states (Table 3). 
Table 1 The prevalence of MHNW, MUNW, MHOW, MUOW, MHO, and MUO based on different criteria

\begin{tabular}{|c|c|c|c|c|c|c|c|}
\hline Criteria & $\begin{array}{l}\text { Age } \\
\text { (years) }\end{array}$ & $\begin{array}{l}\text { MHNW } \\
\%(95 \% \mathrm{Cl})\end{array}$ & $\begin{array}{l}\text { MUNW } \\
\%(95 \% \mathrm{Cl})\end{array}$ & $\begin{array}{l}\text { MHOW } \\
\%(95 \% \mathrm{Cl})\end{array}$ & $\begin{array}{l}\text { MUOW } \\
\%(95 \% \mathrm{Cl})\end{array}$ & $\begin{array}{l}\text { MHO } \\
\%(95 \% \mathrm{Cl})\end{array}$ & $\begin{array}{l}\text { MUO } \\
\%(95 \% \mathrm{Cl})\end{array}$ \\
\hline \multirow[t]{4}{*}{ Meigs et al., 2006 [23] } & $35-44$ & $34.0(32.4-35.7)$ & $2.1(1.6-2.6)$ & $27.8(26.2-29.3)$ & $10.3(9.2-11.3)$ & $14.5(13.3-15.7)$ & $11.3(10.2-12.4)$ \\
\hline & $45-54$ & $28.1(26.4-29.9)$ & $5.6(4.6-6.5)$ & $22.4(20.7-24.0)$ & $18.7(17.1-20.2)$ & $10.1(8.9-11.3)$ & $15.1(13.7-15.5)$ \\
\hline & $55-64$ & $27.0(25.0-29.1)$ & $12.6(11.0-14.2)$ & $14.5(12.8-16.1)$ & $23.8(21.8-25.9)$ & $4.8(3.8-5.8)$ & $17.2(15.5-19.0)$ \\
\hline & $65-70$ & $28.3(24.3-32.3)$ & $16.9(13.5-20.2)$ & $13.1(10.1-16.1)$ & $25.7(21.8-29.7)$ & $3.8(2.1-5.5)$ & $12.2(9.3-15.1)$ \\
\hline ASSP & & $30.3(28.9-31.7)$ & $6.4(5.6-7.1)$ & $22.3(20.9-23.6)$ & $16.8(15.6-17.9)$ & $10.4(9.4-11.3)$ & $13.9(12.8-14.9)$ \\
\hline \multirow[t]{4}{*}{ Aguilar et al., 2008 [24] } & $35-44$ & $26.4(24.8-27.9)$ & $9.8(8.7-10.8)$ & $22.4(20.9-23.8)$ & $15.7(14.4-16.9)$ & $12.7(11.5-13.8)$ & $13.2(12.0-14.3)$ \\
\hline & $45-54$ & $17.8(16.3-19.3)$ & $15.9(14.4-17.4)$ & $17.5(16.0-19.0)$ & $23.5(21.8-25.2)$ & $9.2(8.0-10.3)$ & $16.1(14.6-17.5)$ \\
\hline & $55-64$ & $15.1(13.4-16.7)$ & $24.6(22.5-26.6)$ & $9.9(8.5-11.3)$ & $28.4(26.3-30.5)$ & $4.1(3.2-5.1)$ & $17.9(16.1-19.7)$ \\
\hline & $65-70$ & $13.5(10.4-16.6)$ & $31.7(27.5-35.8)$ & $3.8(2.1-5.5)$ & $35.0(30.7-39.3)$ & $1.7(0.5-2.8)$ & $14.3(11.2-17.5)$ \\
\hline ASSP & & $20.4(19.2-21.7)$ & $16.2(15.1-17.3)$ & $17.0(15.9-18.2)$ & $22.1(20.8-23.3)$ & $9.1(8.2-9.9)$ & $15.2(14.1-16.3)$ \\
\hline \multirow[t]{4}{*}{ Iranian [27] } & $35-44$ & $34.2(32.6-35.8)$ & $1.9(1.4-2.4)$ & $28.3(26.7-29.8)$ & $9.8(8.7-10.8)$ & $13.4(12.2-14.6)$ & $12.4(11.3-13.6)$ \\
\hline & $45-54$ & $29.4(27.6-31.2)$ & $4.3(3.5-5.1)$ & $23.5(21.8-25.2)$ & $17.5(16.0-19.0)$ & $9.5(8.4-10.7)$ & $15.7(14.3-17.2)$ \\
\hline & $55-64$ & $27.9(25.9-30.1)$ & $11.6(10.1-13.1)$ & $13.8(12.2-15.5)$ & $24.5(22.5-26.5)$ & $4.6(3.6-5.6)$ & 17.5 (15.7-19.3) \\
\hline & $65-70$ & $30.8(26.7-34.9)$ & $14.3(11.1-17.5)$ & $10.1(7.4-12.8)$ & $28.7(24.6-32.8)$ & $3.4(1.8-4.9)$ & $12.7(9.7-15.6)$ \\
\hline ASSP & & $31.1(29.7-32.6)$ & $5.5(4.8-6.2)$ & $22.5(21.2-23.8)$ & 16.5 (15.4-17.7) & $9.7(8.8-10.6)$ & $14.6(13.5-15.7)$ \\
\hline
\end{tabular}

Abbreviations: ASSP Age- and sex-standardized prevalence, $C I$ Confidence interval, MHNW Metabolically healthy normal weight, MUNW Metabolically unhealthy normal weight, MHOW Metabolically healthy overweight, MUOW Metabolically unhealthy overweight, MHO Metabolically healthy obesity, MUO Metabolically unhealthy obesity

\section{Discussion}

In the current study, based on the criteria by Meigs et al. [23], the ASSP of MUO, MUOW, and MUNW was found to be $13.9,16.8$, and $6.4 \%$, respectively. The prevalence of these metabolically unhealthy states was only slightly different using the Iranian-specific criteria [27]. However, based on the criteria by Aguilar-Salinas [24], the corresponding percentages were 15.2, 22.1, and $16.2 \%$, respectively. This can simply be justified since meeting WC cut-offs was not required in their criteria and the cut-offs for blood pressure and FPG were set higher, leading to fewer individuals identified as metabolically unhealthy. Moreover, the prevalence of MHO, MHOW, and MHNW was 10.4, 22.3, and 30.3\%, respectively in our study.

Since the 1950s, when Jean Vague observed that obese individuals' predisposition to diabetes and atherosclerosis differs and suggested that this may be due to the difference in body fat distribution, the concept of $\mathrm{MHO}$ was developed [28]. There have been many studies on this subject ever since regarding BMI $\geq 30 \mathrm{~kg} / \mathrm{m}^{2}$ as obesity and considering it a prerequisite for the definition of MHO [29]. Metabolic health has been referred to as the absence of all the components of MetS by some researchers and not meeting the criteria for the diagnosis of MetS by many others [30]. In the current study, we used the criteria proposed by Meigs et al. [23] as the basis of analysis because it was more frequently used in the literature, meanwhile reporting the prevalence of different metabolically healthy and unhealthy states according to two other sets of criteria, namely the criteria proposed by Aguilar-Salinas et al. [24] and the NCEP-ATP III criteria for MetS [25], with cut-offs for WC replaced by $\geq 95 \mathrm{~cm}$ in both men and women for the Iranian population [26].

Comparing the prevalence of $\mathrm{MHO}$ in the current study with what has be en reported in previous studies may not be reliable due to a lack of standardized definition. Depending on the three definitions used in our study, the ASSP prevalence of MHO ranged between 9.1 and $10.4 \%$. Its prevalence has been demonstrated to be 4.2 to $13.6 \%$ in a Chinese adult population based on different definitions [31]. Furthermore, its prevalence has been reported to be $35 \%$ in a recent meta-analysis including 12 cohorts and 7 interventions studies [32] and approximately $12 \%$ in a collaborative analysis of 10 large cohort studies [11]. Aside from the variety of definitions, regional differences seem to contribute to these variations $[11,32]$. Also, the participants of the current study were aged 35-70 years, while other studies were conducted on the adult population, usually defined as individuals over 18 years of age. Another explanation for this inconsistency might be the use of insulin resistance as a part of the diagnostic criteria proposed by Karelis et al. and Wildman et al. in some studies [33, 34].

Another finding of our study was that metabolically unhealthy states including MUO, MUOW, and MUNW were most commonly observed in women, urban residents, and those who were illiterate or unemployed. On the contrary, for metabolically healthy conditions, consisting of MHO, MHOW, and MHNW, it was the other 
Table 2 Characteristics of the study population compared between healthy and unhealthy states

\begin{tabular}{|c|c|c|c|c|c|c|c|c|c|}
\hline Variables & $\begin{array}{l}\text { MHNW } \\
(n=1187)\end{array}$ & $\begin{array}{l}\text { MUNW } \\
(n=249)\end{array}$ & $\begin{array}{l}P \text { - } \\
\text { value }\end{array}$ & $\begin{array}{l}\text { MHOW } \\
(n=873)\end{array}$ & $\begin{array}{l}\text { MUOW } \\
(n=658)\end{array}$ & $\begin{array}{l}P \text { - } \\
\text { value }\end{array}$ & $\begin{array}{l}\text { MHO } \\
(n=407)\end{array}$ & $\begin{array}{l}\text { MUO } \\
(n=543)\end{array}$ & $\begin{array}{l}P \text { - } \\
\text { value }\end{array}$ \\
\hline $\begin{array}{l}\text { Age (years) mean } \pm \\
\text { SD }\end{array}$ & $47.37 \pm 9.50$ & $55.46 \pm 8.90$ & $<0.001$ & $45.90 \pm 8.55$ & $51.88 \pm 8.95$ & $<0.001$ & $44.57 \pm 7.87$ & $49.31 \pm 8.99$ & $<0.001$ \\
\hline \multicolumn{10}{|l|}{ Gender N (\%) } \\
\hline Male & $660(55.6)$ & $98(39.4)$ & $<0.001$ & $467(53.5)$ & $194(29.5)$ & $<0.001$ & $132(32.4)$ & $140(25.8)$ & 0.025 \\
\hline Female & $527(44.4)$ & $151(60.6)$ & & $406(46.5)$ & $464(70.5)$ & & $275(67.6)$ & $403(74.2)$ & \\
\hline \multicolumn{10}{|c|}{ Place of residence $\mathrm{N}(\%)$} \\
\hline Urban & $998(84.1)$ & $193(77.5)$ & 0.012 & $766(87.7)$ & $548(83.3)$ & 0.013 & $368(90.4)$ & $464(85.5)$ & 0.022 \\
\hline Rural & $189(15.9)$ & $56(22.5)$ & & $107(12.3)$ & $110(16.7)$ & & $39(9.6)$ & 79 (14.5) & \\
\hline \multicolumn{10}{|l|}{ Marital status N (\%) } \\
\hline Single & $121(10.2)$ & $35(14.1)$ & 0.075 & $72(8.2)$ & $80(12.2)$ & 0.011 & $32(7.9)$ & $73(13.4)$ & 0.007 \\
\hline Married & $1066(89.8)$ & $214(85.9)$ & & $801(91.8)$ & $578(87.8)$ & & $375(92.1)$ & $470(86.6)$ & \\
\hline \multicolumn{10}{|l|}{ Education N (\%) } \\
\hline Illiterate & $483(40.7)$ & $171(68.7)$ & $<0.001$ & $276(31.6)$ & $384(58.4)$ & $<0.001$ & $153(37.6)$ & $267(49.2)$ & $<0.001$ \\
\hline literate & $704(59.3)$ & $78(31.3)$ & & $597(68.4)$ & $274(41.6)$ & & $254(62.4)$ & $276(50.8)$ & \\
\hline \multicolumn{10}{|l|}{ Occupation N (\%) } \\
\hline Employed & $643(54.2)$ & $86(34.5)$ & $<0.001$ & $500(57.3)$ & 195 (29.6) & $<0.001$ & $164(40.3)$ & $166(30.6)$ & 0.002 \\
\hline Unemployed & $544(45.8)$ & $163(65.5)$ & & $373(42.7)$ & $463(70.4)$ & & $243(59.7)$ & $377(69.4)$ & \\
\hline \multicolumn{10}{|l|}{ Wealth N (\%) } \\
\hline Poor & $524(44.1)$ & $123(49.4)$ & 0.103 & $295(33.8)$ & $266(40.4)$ & 0.003 & $162(39.8)$ & $232(42.7)$ & 0.594 \\
\hline Average & $231(19.5)$ & $53(21.3)$ & & $154(17.6)$ & 129 (19.6) & & $85(20.9)$ & $102(18.8)$ & \\
\hline Rich & $432(36.4)$ & $73(29.3)$ & & $424(48.6)$ & $263(40.0)$ & & $160(39.3)$ & $209(38.5)$ & \\
\hline \multicolumn{10}{|l|}{ Physical activity N (\%) } \\
\hline Low & $256(21.6)$ & $69(27.7)$ & 0.019 & $208(23.8)$ & $190(28.9)$ & 0.004 & $111(27.3)$ & $175(32.2)$ & 0.092 \\
\hline Moderate & $687(57.9)$ & $145(58.2)$ & & $531(60.8)$ & $400(60.8)$ & & $252(61.9)$ & $327(60.2)$ & \\
\hline High & $244(20.6)$ & $35(14.1)$ & & $134(15.3)$ & $68(10.3)$ & & $44(10.8)$ & $41(7.6)$ & \\
\hline $\begin{array}{l}\text { Weight }(\mathrm{kg}) \text { mean } \pm \\
\text { SD }\end{array}$ & $59.06 \pm 8.80$ & $60.26 \pm 7.79$ & 0.031 & $73.72 \pm 8.84$ & $70.91 \pm 8.39$ & $<0.001$ & $86.71 \pm 11.42$ & $86.78 \pm 13.07$ & 0.933 \\
\hline WHR mean \pm SD & $0.89 \pm 0.06$ & $0.96 \pm 0.06$ & $<0.001$ & $0.93 \pm 0.05$ & $0.97 \pm 0.06$ & $<0.001$ & $0.95 \pm 0.06$ & $0.97 \pm 0.06$ & $<0.001$ \\
\hline $\begin{array}{l}\text { Daily calorie intake } \\
\text { (kcal) mean } \pm \mathrm{SD}\end{array}$ & $\begin{array}{l}2879.49 \pm \\
909.46\end{array}$ & $\begin{array}{l}2581.73 \pm \\
798.55\end{array}$ & $<0.001$ & $\begin{array}{l}3072.19 \pm \\
964.31\end{array}$ & $\begin{array}{l}2775.48 \pm \\
887.28\end{array}$ & $<0.001$ & $\begin{array}{l}2992.19 \pm \\
990.85\end{array}$ & $\begin{array}{l}2867.24 \pm \\
940.00\end{array}$ & 0.048 \\
\hline
\end{tabular}

Abbreviations: $N$ Number, SD Standard deviation, WHR Waist-to-hip ratio, MHNW Metabolically healthy normal weight, $M U N W$ Metabolically unhealthy normal weight, MHOW Metabolically healthy overweight, MUOW Metabolically unhealthy overweight, MHO Metabolically healthy obesity, MUO Metabolically unhealthy obesity

way around; they were more frequent in men, rural residents, and those who were literate or employed. Even so, both metabolically healthy and unhealthy states were more common among those who were married, did not smoke, or were at the extremes regarding wealth (the rich and the poor). Regardless of age and gender, other factors have rarely been addressed in previous studies.

In contrast to the findings of our study, $\mathrm{MHO}$ has been reported to be more prevalent in women rather than men $[11,31]$. This is in part due to the fact that the female participants of the current study appear to have a specific lifestyle with regard to physical activity, leading to many women falling into the MUO category; approximately $90 \%$ of the women in this study had low to moderate physical activity (data not shown). Difference in gender distribution, that is the distribution of men and women in the $\mathrm{MHO}$ and MUO groups of these studies compared to ours, can be another explanatory reason. The overall proportion of women could have been higher in these studies.

MHO decreased with age in our study, which is in line with the findings of van Vliet-Ostaptchouk et al. [11]. Besides, we also found that the odds of all metabolically unhealthy states elevated with increasing age, except for MUO whose odds decreased by 1.03 from the 55-64-year age group to the 65-70-year age group. A considerable variation in the prevalence of obesity phenotypes with age has been reported by Liu 
Table 3 Binary logistic regression analysis for the association of MUNW, MUOW, and MUO with socio-demographic characteristics

\begin{tabular}{|c|c|c|c|c|c|c|c|c|c|}
\hline \multirow[t]{2}{*}{ Variable } & \multicolumn{3}{|c|}{$\begin{array}{l}\text { MUNW }(n=249) \\
\text { Total }=1436\end{array}$} & \multicolumn{3}{|c|}{$\begin{array}{l}\text { MUOW }(n=658) \\
\text { Total }=1531\end{array}$} & \multicolumn{3}{|c|}{$\begin{array}{l}\text { MUO }(n=543) \\
\text { Total }=950\end{array}$} \\
\hline & $\mathrm{aOR}$ & $95 \% \mathrm{Cl}$ & $P$-value & $\mathrm{aOR}$ & $95 \% \mathrm{Cl}$ & $P$-value & $\mathrm{aOR}$ & $95 \% \mathrm{Cl}$ & $P$-value \\
\hline \multicolumn{10}{|l|}{ Gender } \\
\hline Male* & 1.00 & & & 1.00 & & & 1.00 & & \\
\hline Female & 1.59 & $0.78-3.23$ & 0.202 & 1.88 & $1.18-2.99$ & 0.008 & 1.05 & $0.62-1.78$ & 0.857 \\
\hline \multicolumn{10}{|c|}{ Age groups (years) } \\
\hline $35-44^{*}$ & 1.00 & & & 1.00 & & & 1.00 & & \\
\hline $45-54$ & 3.31 & $2.06-5.32$ & $<0.001$ & 1.92 & $1.45-2.52$ & $<0.001$ & 1.74 & $1.26-2.41$ & 0.001 \\
\hline $55-64$ & 7.02 & $4.26-11.57$ & $<0.001$ & 3.10 & $2.20-4.39$ & $<0.001$ & 4.28 & $2.76-6.62$ & $<0.001$ \\
\hline $65-70$ & 7.48 & $3.88-14.40$ & $<0.001$ & 3.74 & $2.18-6.43$ & $<0.001$ & 3.25 & $1.42-7.45$ & 0.005 \\
\hline \multicolumn{10}{|l|}{ Place of residence } \\
\hline Urban* & 1.00 & & & 1.00 & & & 1.00 & & \\
\hline Rural & 1.10 & $0.74-1.63$ & 0.655 & 1.10 & $0.79-1.54$ & 0.561 & 1.37 & $0.88-2.15$ & 1.166 \\
\hline \multicolumn{10}{|l|}{ Marital status } \\
\hline Single & 1.01 & $0.61-1.67$ & 0.963 & 0.79 & $0.54-1.17$ & 0.242 & 1.42 & $0.88-2.28$ & 0.151 \\
\hline Married* & 1.00 & & & 1.00 & & & 1.00 & & \\
\hline \multicolumn{10}{|l|}{ Education } \\
\hline Illiterate & 1.26 & $0.84-1.88$ & 0.260 & 1.43 & $1.09-1.87$ & 0.010 & 1.04 & $0.74-1.46$ & 0.824 \\
\hline Literate $^{*}$ & 1.00 & & & 1.00 & & & 1.00 & & \\
\hline \multicolumn{10}{|l|}{ Occupation } \\
\hline Unemployed* & 1.00 & & & 1.00 & & & 1.00 & & \\
\hline Employed & 1.22 & $0.79-1.90$ & 0.376 & 0.75 & $0.55-1.02$ & 0.068 & 1.01 & $0.67-1.53$ & 0.972 \\
\hline \multicolumn{10}{|l|}{ Wealth } \\
\hline Poor* & 1.00 & & & 1.00 & & & 1.00 & & \\
\hline Average & 1.15 & $0.76-1.75$ & 0.519 & 1.33 & $0.96-1.84$ & 0.089 & 0.84 & $0.58-1.22$ & 0.356 \\
\hline Rich & 0.98 & $0.67-1.45$ & 0.931 & 0.97 & $0.75-1.27$ & 0.844 & 1.05 & $0.76-1.45$ & 0.789 \\
\hline \multicolumn{10}{|l|}{ WHR } \\
\hline Low $^{*}$ & 1.00 & & & 1.00 & & & 1.00 & & \\
\hline Moderate & 0.67 & $0.37-1.22$ & 0.192 & 1.04 & $0.70-1.56$ & 0.821 & 1.29 & $0.75-2.23$ & 0.357 \\
\hline High & 1.08 & $0.52-2.24$ & 0.833 & 1.17 & $0.72-1.89$ & 0.526 & 1.32 & $0.75-2.32$ & 0.342 \\
\hline \multicolumn{10}{|l|}{ Physical Activity } \\
\hline Low & 1.45 & $0.87-2.42$ & 0.155 & 1.20 & $0.81-1.80$ & 0.363 & 1.35 & $0.80-2.27$ & 0.264 \\
\hline Moderate & 1.16 & $0.74-1.82$ & 0.513 & 1.20 & $0.84-1.72$ & 0.312 & 1.35 & $0.83-2.19$ & 0.226 \\
\hline High* & 1.00 & & & 1.00 & & & 1.00 & & \\
\hline BMl & 1.20 & $1.07-1.36$ & 0.003 & 1.01 & $0.92-1.11$ & 0.801 & 0.96 & $0.91-1.02$ & 0.202 \\
\hline WC & 1.09 & $1.05-1.14$ & $<0.001$ & 1.06 & $1.03-1.09$ & $<0.001$ & 1.04 & $1.02-1.07$ & 0.001 \\
\hline
\end{tabular}

Abbreviations: MUO mEtabolically unhealthy obesity, MUOW Metabolically unhealthy overweight, MUNW Metabolically unhealthy normal weight, aOR Adjusted odds ratio, $\mathrm{Cl}$ Confidence interval

* Reference category

et al. [31]. The transient nature of MHO has been suggested by some studies including a follow-up study from England reporting the transition of $44.5 \%$ of individuals with $\mathrm{MHO}$ into MUO within 8 years [35]. This can partly explain the increase in the odds of metabolically unhealthy conditions with advancing age in our study.
Additionally, higher $\mathrm{WC}$ was significantly correlated with all metabolically unhealthy states in the current study, confirming that fat distribution and abdominal obesity are more important factors when it comes to metabolic health compared to BMI [5, 36].

Also, interestingly, we observed a significant association between BMI and MUNW but not with MUOW 
or MUO. This means that even when the BMI is within the normal limits $(<25 \mathrm{~kg} / \mathrm{m} 2)$, higher BMI is associated with increased odds of being metabolically unhealthy. Since the same correlation was not observed between BMI and MUOW or MUO, it can be speculated that although there has been no measurement of body fat in the current study, higher BMI within the normal range can translate into higher body fat in this group, which is probably not the case in overweight and obesity.

Notably, the main reason for categorization of individuals into metabolically healthy and unhealthy subgroups is to assess their cardio-metabolic risk and identify those at higher risk of cardiovascular morbidity or mortality in the long run needing special attention. Longitudinal studies best serve this purpose. Hence, a major limitation of the current study was its cross-sectional design. Besides, data regarding insulin resistance, interleukin 6 (IL-6), tumor necrosis factor- $\alpha$ (TNF- $\alpha$ ), and other inflammatory markers were lacking in our study. However, the participants of this cohort are being followed and by analyzing their outcomes after 3 and 5 years of followup, we will be able to evaluate the significance of $\mathrm{MHO}$, MHOW, or MHNW in this population. Moreover, similar to previous studies we will be able to determine the transition rate from metabolically healthy to unhealthy states and its association with patients' outcomes.

Noteworthy, to select individuals that are most representative of the whole population in the South of Iran, Bandare-Kong city had been chosen for recruitment of the PERSIAN Cohort participants. This city has the lowest immigration and emigration rate. Meanwhile, its population is quite homogeneous with regard to lifestyle and other factors. However, we cannot determine to what extent the results of the current study reflect the true burden of metabolically unhealthy states in the whole population, which can be referred to as another limitation of the current study.

\section{Conclusions}

Among the metabolically unhealthy conditions, the highest prevalence belonged to individuals with MUOW. Higher age and WC were significantly correlated with all metabolically unhealthy states, while illiteracy and higher BMI were only associated with MUOW and MUNW, respectively. Complementary longitudinal studies reporting the outcomes and inflammatory indices in the participants of the present study are required to confirm our findings and illustrate the significance of metabolic health in this population. Many guidelines emphasize on the significance of weight loss as a major factor to control and prevent harmful complications such as cardiovascular diseases. However, our results show that metabolic health rather than weight loss alone should be the focus and objective of public prevention programs.

\section{Abbreviations}

ASSP: Age and sex-standardized prevalence; BMI: Body mass index; BP: Blood pressure; Cl: Confidence interval; DBP: Diastolic blood pressure; FPG: Fasting plasma glucose; HC: Hip circumference; HDL: High-density lipoprotein;

IL: Interleukin; METs: Metabolic equivalent of tasks; MetS: Metabolic syndrome; MHNW: Metabolically healthy normal weight; MHO: Metabolically healthy obesity; MHOW: Metabolically healthy overweight;

MUNW: Metabolically unhealthy normal weight; MUO: Metabolically unhealthy obesity; MUOW: Metabolically unhealthy overweight; OR: Odds ratio; PERSIAN: Prospective Epidemiological Research Studies in IrAN; SBP: Systolic blood pressure; SPSS: Statistical Package for the Social Sciences; TG: Triglyceride; TNF: Tumor necrotizing factor; WC: Waist circumference; WHR: Waist-to-hip ratio

\section{Acknowledgments}

BKNCD is a part of PERSIAN national cohort and we would like to thank Professor Reza Malekzadeh, Deputy of Research and Technology at the Ministry of Health and Medical Education of Iran and Director of the PERSIAN cohort, Dr. Hossein Poustchi, Executive Director of the PERSIAN cohort, and Professor Teamur Aghamolaei, Vice Chancellor for Technology and Research, Hormozgan University of Medical Sciences for all their supports during design and running of BKNCD. The Iranian Ministry of Health and Medical Education has contributed to the funding used in the PERSIAN Cohort through grant number 700/534.

\section{Authors' contributions}

MK designed the study and GZ wrote the manuscript. RS and MM analyzed and interpreted the data. AN performed the technical revision of the manuscript. All authors read and approved the final manuscript.

\section{Funding}

The Iranian Ministry of Health and Medical Education has contributed to the funding used in the PERSIAN Cohort through grant number 700/534.

\section{Availability of data and materials}

The datasets used and/or analyzed during the current study are available from the corresponding author on reasonable request.

\section{Declarations}

Ethics approval and consent to participate

The study was approved by the Institutional Review Board of Hormozgan University of Medical Sciences and it complies with the statements of the Declaration of Helsinki. The associated ethics code is: IR.HUMS.REC.1399.447. Informed consent was obtained from all subjects and from a parent and/or legal guardian for vulnerable population.

\section{Consent for publication}

Not applicable.

\section{Competing interests}

The authors declare that they have no competing interests.

\section{Author details}

${ }^{1}$ Cardiovascular Research Center, Hormozgan University of Medical Sciences, Bandar Abbas, Iran. ${ }^{2}$ Cellular and Molecular Medicine Department, Faculty of Medicine, University of Ottawa, Ottawa, Canada. ${ }^{3}$ Endocrinology and Metabolism Research Center, Hormozgan University of Medical Sciences, Bandar Abbas, Iran. ${ }^{4}$ Molecular Medicine Research Center, Hormozgan Health Institute, Hormozgan University of Medical Sciences, Bandar Abbas, Iran.

Received: 21 December 2020 Accepted: 26 October 2021

Published online: 05 November 2021

\section{References}

1. Mozaffarian D, Benjamin EJ, Go AS, Arnett DK, Blaha MJ, Cushman M, et al. Executive summary: heart disease and stroke statistics - 2016 update: a report from the American Heart Association. Circulation. 2016;133(4):447-54. https://doi.org/10.1161/CIR.0000000000000366.

2. Goday A, Calvo E, Vázquez LA, Caveda E, Margallo T, Catalina-Romero C, et al. Prevalence and clinical characteristics of metabolically healthy obese 
individuals and other obese/non-obese metabolic phenotypes in a working population: results from the Icaria study. BMC Public Health. 2016;16(1):248. https://doi.org/10.1186/s12889-016-2921-4.

3. Aune D, Sen A, Norat T, Janszky I, Romundstad P, Tonstad S, et al. Body mass index, abdominal fatness, and heart failure incidence and mortality: a systematic review and dose-response meta-analysis of prospective studies. Circulation. 2016;133(7):639-49. https://doi.org/10.1161/CIRCULATIONAHA.11 5.016801 .

4. Phillips CM. Metabolically healthy obesity: personalised and public health implications. Trends Endocrinol Metab. 2016;27(4):189-91. https://doi.org/1 0.1016/j.tem.2016.02.001

5. Stefan N, Häring H-U, Hu FB, Schulze MB. Metabolically healthy obesity: epidemiology, mechanisms, and clinical implications. Lancet Diabetes Endocrinol. 2013;1(2):152-62. https://doi.org/10.1016/S2213-8587(13)70062-7.

6. Samocha-Bonet D, Dixit VD, Kahn CR, Leibel RL, Lin X, Nieuwdorp M, et al. Metabolically healthy and unhealthy obese-the 2013 S tock C onference report. Obes Rev. 2014;15(9):697-708. https://doi.org/10.1111/obr.12199.

7. Fabbrini E, Yoshino J, Yoshino M, Magkos F, Luecking CT, Samovski D, et al. Metabolically normal obese people are protected from adverse effects following weight gain. J Clin Invest. 2015;125(2):787-95. https://doi.org/1 $0.1172 / \mathrm{JCl} 78425$.

8. Karelis AD, Messier V, Brochu M, Rabasa-Lhoret R. Metabolically healthy but obese women: effect of an energy-restricted diet. Diabetologia. 2008;51(9): 1752-4. https://doi.org/10.1007/s00125-008-1038-4.

9. Liu XM, Liu YJ, Zhan J, He QQ. Overweight, obesity and risk of all-cause and cardiovascular mortality in patients with type 2 diabetes mellitus: a doseresponse meta-analysis of prospective cohort studies. Eur J Epidemiol. 2015: 30(1):35-45. https://doi.org/10.1007/s10654-014-9973-5.

10. Phillips CM. Metabolically healthy obesity: definitions, determinants and clinical implications. Rev Endocr Metab Dis. 2013;14(3):219-27. https://doi. org/10.1007/s11154-013-9252-X

11. van Vliet-Ostaptchouk JV, Nuotio M-L, Slagter SN, Doiron D, Fischer K, Foco $L$, et al. The prevalence of metabolic syndrome and metabolically healthy obesity in Europe: a collaborative analysis of ten large cohort studies. BMC Endocr Disord. 2014;14(1):9. https://doi.org/10.1186/1472-6823-14-9.

12. Primeau V, Coderre L, Karelis AD, Brochu M, Lavoie ME, Messier V, et al. Characterizing the profile of obese patients who are metabolically healthy. Int J Obes. 2011;35(7):971-81. https://doi.org/10.1038/ijo.2010.216.

13. Brochu M, Tchernof A, Dionne IJ, Sites CK, Eltabbakh GH, Sims EAH, et al. What are the physical characteristics associated with a normal metabolic profile despite a high level of obesity in postmenopausal women? J Clin Endocrinol Metab. 2001:86(3):1020-5.

14. Karelis AD, Faraj M, Bastard J-P, St-Pierre DH, Brochu M, Prud'homme D, et al. The metabolically healthy but obese individual presents a favorable inflammation profile. J Clin Endocrinol Metab. 2005:90(7):4145-50. https:// doi.org/10.1210/jc.2005-0482

15. Colangelo LA, Vu T-HT, Szklo M, Burke GL, Sibley C, Liu K. Is the association of hypertension with cardiovascular events stronger among the lean and normal weight than among the overweight and obese? The multi-ethnic study of atherosclerosis. Hypertension. 2015;66(2):286-93. https://doi.org/1 0.1161/HYPERTENSIONAHA.114.04863.

16. Sung K-C, Ryu S, Cheong ES, Kim BS, Kim BJ, Kim Y-B, et al. All-cause and cardiovascular mortality among Koreans: effects of obesity and metabolic health. Am J Prev Med. 2015;49(1):62-71. https://doi.org/10.1016/j.amepre.2 015.02.010.

17. Poustchi H, Eghtesad S, Kamangar F, Etemadi A, Keshtkar A-A, Hekmatdoost A, et al. Prospective epidemiological research studies in Iran (the PERSIAN cohort study): rationale, objectives, and design. Am J Epidemiol. 2018;187(4): 647-55. https://doi.org/10.1093/aje/kwx314.

18. World Health O. World Health Organization body mass index (BMI) classification. Available at https://www.euro.who.int/en/health-topics/disea se-prevention/nutrition/a-healthy-lifestyle/body-mass-index-bmi.

19. Craig $C L$, Marshall $A L$, Sjöström M, Bauman AE, Booth ML, Ainsworth BE, et al. International physical activity questionnaire: 12-country reliability and validity. Med Sci Sports Exerc. 2003;35(8):1381-95. https://doi.org/10.1249/01. MSS.0000078924.61453.FB.

20. Pasdar $Y$, Najafi F, Moradinazar M, Shakiba E, Karim H, Hamzeh B, et al. Cohort profile: Ravansar Non-Communicable Disease cohort study: the first cohort study in a Kurdish population. Int J Epidemiol. 2019;48(3):682-3f.

21. Nedjat S, Hosseinpoor AR, Forouzanfar MH, Golestan B, Majdzadeh R. Decomposing socioeconomic inequality in self-rated health in Tehran. J
Epidemiol Community Health. 2012;66(6):495-500. https://doi.org/10.1136/ jech.2010.108977.

22. World Health Organization. Waist circumference and waist-hip ratio: report of a WHO expert consultation, Geneva, 8-11 December 2008. World Health Organization. 2011. https://apps.who.int/iris/handle/10665/44583.

23. Meigs JB, Wilson PWF, Fox CS, Vasan RS, Nathan DM, Sullivan LM, et al. Body mass index, metabolic syndrome, and risk of type 2 diabetes or cardiovascular disease. J Clin Endocrinol Metab. 2006;91(8):2906-12. https:// doi.org/10.1210/jc.2006-0594.

24. Aguilar-Salinas CA, García EG, Robles L, Riano D, Ruiz-Gomez DG, GarcíaUlloa AC, et al. High adiponectin concentrations are associated with the metabolically healthy obese phenotype. J Clin Endocrinol Metab. 2008; 93(10):4075-9. https://doi.org/10.1210/jc.2007-2724.

25. Expert Panel on Detection E. Executive summary of the third report of the National Cholesterol Education Program (NCEP) expert panel on detection, evaluation, and treatment of high blood cholesterol in adults (Adult Treatment Panel III). JAMA. 2001;285(19):2486.

26. Fereidoun Azizi M, Davood Khalili M, Hassan Aghajani M, Alireza Esteghamati M, Farhad Hosseinpanah M, Alireza Delavari M, et al. Appropriate waist circumference cut-off points among Iranian adults: the first report of the Iranian National Committee of obesity. Arch Iran Med. 2010;13(3):243.

27. Azizi F, Hadaegh F, Khalili D, Esteghamati AR, Hossein PF, Delavari AR, et al. Appropriate definition of metabolic syndrome among Iranian adults: report of the Iranian National Committee of obesity. 2010.

28. Vague J. The degree of masculine differentiation of obesities: a factor determining predisposition to diabetes, atherosclerosis, gout, and uric calculous disease. Am J Clin Nutr. 1956;4(1):20-34. https://doi.org/10.1093/a jen/4.1.20.

29. Rey-Lopez JP, De Rezende LF, Pastor-Valero M, Tess BH. The prevalence of metabolically healthy obesity: a systematic review and critical evaluation of the definitions used. Obes Rev. 2014;15(10):781-90. https://doi.org/10.1111/ obr.12198.

30. Blüher M. Metabolically healthy obesity. Endocr Rev. 2020;41(3):bnaa004

31. Liu C, Wang C, Guan S, Liu H, Wu X, Zhang Z, et al. The prevalence of metabolically healthy and unhealthy obesity according to different criteria. Obes Facts. 2019;12(1):78-90. https://doi.org/10.1159/000495852.

32. Lin $H$, Zhang $L$, Zheng $R$, Zheng $Y$. The prevalence, metabolic risk and effects of lifestyle intervention for metabolically healthy obesity: a systematic review and meta-analysis: A PRISMA-compliant article. Medicine (Baltimore). 2017;96(47):e8838. https://doi.org/10.1097/MD.000000000000883 8.

33. Wildman RP, Muntner P, Reynolds K, McGinn AP, Rajpathak S, Wylie-Rosett J, et al. The obese without cardiometabolic risk factor clustering and the normal weight with cardiometabolic risk factor clustering: prevalence and correlates of 2 phenotypes among the US population (NHANES 1999-2004). Arch Intern Med. 2008;168(15):1617-24. https://doi.org/10.1001/archinte.1 68.15 .1617

34. Karelis AD, Brochu M, Rabasa-Lhoret R. Can we identify metabolically healthy but obese individuals (MHO)? Diabetes Metab. 2004;30(6):569-72. https://doi.org/10.1016/S1262-3636(07)70156-8.

35. Hamer M, Bell JA, Sabia S, Batty GD, Kivimäki M. Stability of metabolically healthy obesity over 8 years: the English longitudinal study of ageing. Eur J Endocrinol. 2015;173(5):703-8. https://doi.org/10.1530/EJE-15-0449.

36. Stefan N, Schick F, Häring H-U. Causes, characteristics, and consequences of metabolically unhealthy normal weight in humans. Cell Metab. 2017;26(2): 292-300. https://doi.org/10.1016/j.cmet.2017.07.008.

\section{Publisher's Note}

Springer Nature remains neutral with regard to jurisdictional claims in published maps and institutional affiliations. 